http://sciforum.net/conference/ece-1

Conference Proceedings Paper - Energies „, Whither Energy Conversion? Present Trends, Current Problems and Realistic Future Solutions”

\title{
Why are some of the Sama-Szargut Second Law rules routinely violated in practical applications?
}

\author{
Enrico Sciubba \\ Dept. of Mechanical \& Aerospace Engineering, University of Roma Sapienza; \\ E-Mail: enrico.sciubba@uniroma1.it
}

Received: 17 December 2013 / Accepted: 18 March 2014 / Published: 19 March 2014

\begin{abstract}
In 1989, Gaggioli, Sama and Qian published a series of 10 "second law guidelines" for design and process engineers, which were discussed for some time in thermodynamic conferences and papers under the name of "the Gaggioli-Sama rules", though some of them had been previously published by Sama between 1980 and 1983. These guidelines are in essence a list of "second law errors" to avoid in the design of energy conversion systems. The list was later rearranged several times, and its latest version, containing 21 rules, was published by Dominick Sama and Jan Szargut in 1995. Ever since, these guidelines came to be known as "the Sama-Szargut rules"

The rules are sound, well-formulated, insightful, and reflect a thermodynamicist's idea that the "best design" is the one that minimizes the overall irreversibility in the process or plant under consideration. Characteristically, the idea of "optimality" is completely absent from all published formulations, the insistence being on the extensive inclusion of second law reasoning into design decisions. One would therefore expect that most, if not all, of the rules be routinely implemented in new designs and in retrofit projects. It turns out, that the contrary is rather true: even a superficial survey of some of the current most common energy conversion installations shows that most of the rules are actually disregarded in practice.

This paper contends that the reason for this apparently irrational behavior is the neglection in the engineering design decision of the real cost of installation, operation and dismantling of a plant. It is argued that, if the production cost is assessed in terms of equivalent primary exergy and a proper exergy accounting for the externalities is introduced, the Sama-Szargut rules can be directly interpreted in this sense, and abidance by the rules results in the reduction of the resource cost for any given objective.
\end{abstract}


Keywords: exergy; Sama-Szargut rules; extended exergy; product cost; exergy footprint

\section{Nomenclatur}

\begin{tabular}{|c|c|c|c|}
\hline c & cost & $\mathrm{M} 2, € / \mathrm{yr}$ & Monetary circulation \\
\hline $\mathrm{C}, \mathrm{W} / \mathrm{K}$ & Heat capacity & $\mathrm{N}$ & Number of workhours \\
\hline $\mathrm{c}_{\mathrm{p}}, \mathrm{J} /(\mathrm{kgK})$ & Specific heat & $\mathrm{P}$ & "Product" \\
\hline E,e, J; J/unit & Exergy, specific exergy & $\mathrm{P}, \mathrm{W}$ & Shaft power (section 4.3.2) \\
\hline EE,ee, J,J/unit & Extended exergy & RO & Reverse Osmosis desalination \\
\hline $\mathrm{F}$ & "Fuel” & $\mathrm{T}, \mathrm{K}$ & Temperature \\
\hline $\mathrm{G}, \mathrm{J}$ & Gibbs energy & TIT, K & Turbine Inlet T \\
\hline $\mathrm{H}, \mathrm{J}$ & Enthalpy & $\mathrm{V}, \mathrm{m}^{3}$ & Volume \\
\hline $\mathrm{K}, €$ & Capital & \multicolumn{2}{|c|}{ Greek symbols } \\
\hline L, workhours & Labour & $\alpha, \beta$ & EEA econometric coefficients \\
\hline $\mathrm{m}, \mathrm{kg} / \mathrm{s}$ & Mass flow rate & $\Delta$ & Gradient \\
\hline MSF & Multistage Flash desalination & $\pi, \sigma$ & Beyer-Kotas coefficients \\
\hline
\end{tabular}

\section{Introduction}

Expanding on previous works by Sama [21,22], Gaggioli, Sama and Qian published in 1989 a series of 10 "second law guidelines" for design and process engineers, known at that time as "the GaggioliSama rules" [25]. These guidelines are a very well-thought list of "second law errors" that must be avoided in the design of energy conversion systems. The list was later rearranged several times [10,14,23,24], and its currently accepted version, containing 21 rules, was published by Dominick Sama and Jan Szargut in 1995 [30]: ever since, they are quoted as “the Sama-Szargut rules”.

The rules reflect a thermodynamicist's idea that the "best design" is the one that minimizes the overall irreversibility in the process or plant under consideration. Significantly, the concept of "optimality" is completely absent from the rules, the insistence being on the extensive inclusion of second law reasoning into design decisions. In view of the evergrowing incentive to reduce resource use and to optimize the matching between the primary source and the final use, it might be expected that all of the rules be routinely implemented, both in new designs and in retrofit projects. It turns out, that the contrary is rather true: a careful survey of the current most common energy conversion installations shows that most of the rules are actually disregarded in practice.

This paper contends that the reason for this apparently irrational behavior has its origin in the fact that current engineering design decision are based on a distorted view of the real cost of installation, operation and dismantling of a plant. It is argued that, if the production cost is assessed in terms of equivalent primary exergy and a proper exergy accounting for the externalities is introduced, the Sama-Szargut rules can be directly interpreted in their original sense, and abidance by the rules results in the reduction of the resource cost for any given objective. 


\section{A Brief Discussion of the Sama-Szargut $2^{\text {nd }}$ Law Based Rules}

For the purpose of this discussion, it is convenient to classify the Sama-Szargut rules on the basis of their major field of application. This classification is of course somewhat arbitrary, because some of the rules intrinsically pertain to more than one group, but it is useful for focusing on the objective of this paper. A commented list is offered below.

\subsection{General Process-Related Rules}

1. Do not use excessively large or excessively small thermodynamic driving forces in process operations.

This rule was originally formulated for heat exchangers, and prescribes that the temperature differences between the heating and heated fluid should not be too small (because the necessary heat transfer area will be too large) but also not too high (because the efficiency of transfer process depends inversely on the $\Delta \mathrm{T}$ ). The rule applies equally well to chemical, electrical and fluid processes where the exergy decrement of one stream is the „fuel“ ${ }^{1}$ used to increase the exergy content of another stream: the exergy destruction is proportional in all cases to the square of the driving force $(\Delta \mathrm{T}, \Delta \mathrm{G}, \Delta \mathrm{V}, \Delta \mathrm{H} \&)$.

2. Minimize the mixing of streams with differences in temperature, pressure or chemical composition.

The mixing of streams with different temperatures leads to unnecessary irreversible heat transfer. If the mixed streams have different composition (e.g. in the oxygen-enrichment of process air) a portion of the high-exergy stream is destroyed. If the streams streams have different pressures or velocities the mixing results in a highly irreversible momentum transfer by viscous actions from one of the fluids to the other.

3. Remember that in cyclic and pseudo-cyclic processes driven by chemical, nuclear or mechanical energy the rejection of heat to the environment in condensers of turbines, refrigerators, etc., is a reflection of the irreversibilities within the plant.

A decrease in heat loss from the condensers (which represents a discharge of exergy into the environment) can only be attained by the reduction of irreversibilities within the plant. The rejection of heat in condensers cannot be eliminated by the introduction of internal „improvements“, like for example the recompression of vapour in evaporator systems: only the location of this rejection is changed (it appears some other section of the plant, possibly at a higher temperature).

\footnotetext{
1 Throughout this paper, the words "fuel” and "product” are used in the acception proposed by Tsatsaronis [32,33], i.e. as “used exergy input” and “useful exergy output” respectively.
} 
4. Fans or compressors should be designed to operate on the coolest streams that participate to the process.

The driving power of compressors or fans is proportional to the fluid density, and hence -for the same inlet pressure and the same pressure ratio- it decreases with the inlet temperature.

5. Avoid the compression of steam which has been previously expanded.

The exergy destruction affects twice the same stream in this case, and the exergy destruction in the expansion causes a lower efficiency -ceteris paribus- in the compressor.

6. Try to introduce cogeneration processes that simultaneously produce two or more useful effects.

A cogeneration process (e.g. joint production of heat and electricity, of desalinated water and power, of two different chemicals) brings about a shortening of the chain of processes and therefore ensures a reduction of exergy destruction within the entire system (see rule 17). Furthermore, synergic effects in the process may lead to the generation of more units of „products“ with the same amount of „fuel“.

7. Consider the influence of possible changes in the energy management of a part of a system on the exergy destructions in other links of the system.

Thermo-Economics has convincingly shown that the separate optimization of one unit of an energy system is not necessarily convenient for the exergy efficiency of the plant, because of the influence of the system connectivity (feedbacks, forward links, bifurcations, etc.a quantitative measure is provided by the Beyer-Kotas coefficients [2,9]).

8. Some 2nd Law inefficiencies cannot be avoided, others can. Concentrate on those which can.

This is the basis of the novel Tsatsaronis“ „avoidable costs“ method [34], and represents a sort of Occam’s razor for engineering decisions about „local“ improvements to a process.

\subsection{Heat Exchange-Related Rules}

9. Do not discard heat at high temperature to the ambient or to cooling water, and do not heat refrigerated streams with hot streams or with cooling water.

High temperature waste heat has a relatively large exergy, which ought to be partially recovered by proper cascading processes. Simmetrically, in most cooling installations, the exergy of discarded refrigerated streams can be partially recovered by heat exchangers where sub-ambient process streams need to be cooled.

10. When choosing streams for heat exchange, try to match streams where the final temperature of one is close to the initial temperature of the other. 
This reduces the logarithmic mean temperature difference of the process and ensures that the maximum exergy is recovered in the heat exchange process.

11. The flow heat capacities $\left(c_{p} m\right)$ of the streams exchanging heat should be similar. If large differences appear, consider partitioning the stream having a higher heat capacity between two or more heat exchangers heated (or cooled) by additional streams.

Large differences in heat capacity lead to a lower $\Delta \mathrm{T}$ in the large-C stream, increase the LMTD of the exchange and cause a non uniform distribution of the exergy destruction within the heat exchanger.

12. Any counter-current process is generally more thermodynamically efficient than its parallel equivalent.

Counter-flow heat exchangers and selective membranes display the smallest exergy destructions (see rule 1). Application of parallel current processes is acceptable only in the presence of casespecific design constraints.

\subsection{Viscous Destructions-Related Rules}

13. Exergy destructions due to hydraulic friction or irreversible heat transfer are the larger, the lower is the temperature in the process. Minimize these destructions especially below the ambient temperature.

The viscous exergy destruction is directly proportional to the fluid viscosity (that on its own increases with decreasing $\mathrm{T}$ ) and inversely proportional to $\mathrm{T}$. The thermal exergy destruction is inversely proportional to the second power of $\mathrm{T}$.

14. Minimize the throttling of steam or other gases.

Throttling introduces a destruction of exergy which could be otherwise recovered, and is usually without economic justification.

15. Eliminate leaks in pipelines, valves and combustion chambers.

Even small leakages of compressed gases, of hot combustion gases or unplanned air injection into combustion gas ducts or combustion chambers lead to a large decrease of energy efficiency of the total system (see rules 2, 5, 3, 14).

\subsection{Exergy Cost-Related Rules}

16. If you can reduce some exergy destruction, check whether you are increasing another exergy destruction or causing yet another to appear. 
This is related to rule 7 above: the connectivity of a plant (its structure) ought to be taken into account, for instance by proper use of the Beyer-Kotas coefficients of structural and external bond, $\sigma$ and $\pi$.

17. Avoid to unduly extend the chain of thermodynamic processes for a certain product.

Every newly inserted link in the chain is a real process and introduces new exergy destructions.

18. Remember that the specific exergy cost increases "downstream" along the chain of processes.

This is again a contribution of Thermo-Economics: the specific cost of the „fuel“ exergy in the j-th component of a process is smaller than the specific exergy cost of the product, and if this product is used downstream as a „fuel“ in the $(j+1)$ th component, the specific exergy cost of the $(j+1)$ th „products“ increases in turn.

\subsection{Monetary Cost-Related Rules}

19. When exchanging heat between two streams, minimize the use of intermediate heat transfer fluids.

The application of an intermediate fluid always increases the total heat transfer area. It may be justified in specific cases, because of local constraints or when thermal energy must be transported across long distances.

20. Accept an exergy destruction only if it is indispensable for the reduction of investment expenses. Exergy destructions not having any economic justification should be treated as the result of an engineer's error.

This is related again to Tsatsaronis` avoidable and unavoidable cost formulation: the exergy destruction due to irreversible heat transfer cannot be eliminated from a heat exchanger, because without temperature differences the heat transfer area would be infinitely great; the exergy destruction due to viscous effects in a compressor can be partially but not totally eliminated, etc.

21. Try to reduce the exergy destructions in places where they are the greatest and in places where they are the most expensive.

The destruction of exergy in the final „products“ is the most costly, because their exergy content is already charged with both the exergy and the capital cost of the upstream processes.

\section{Some Examples of Intentional Violations of the Rules in Engineering Applications}

Without any claim of completeness, in this section I shall examine some of the most blatant violations of the Sama-Szargut rules that can be detected in current energy-conversion plants and processes. The list is by no means final, and is presented here for the sole purpose of discussing the reasons for these violations. 


\subsection{Electrical Heaters}

Space heating devices that make direct or indirect use of electricity as a fuel are common in Europe and in North America. The operation of such devices violates rule 8, because the exergy destruction in the process could be easily removed by resorting to some other heating method; it also violates rules 1 and 9, because the temperature of the radiating element is much higher than that of the ambient to be heated; it obviously violates rule 17, because the chain of processes that generate electricity is a long and complex one, especially if the primary fuel is fossil exergy (including nuclear); finally, it violates rule 21 , because the largest part of the exergy destruction takes place in the final step of the process. The exergy efficiency of several space heating systems is shown in figure 1: for the thermally recovered photovoltaic plant (PVT) the results are taken from [6,13]; for all other plants, they are adapted from $[3,8]$. Notice that the relatively high average second-law efficiencies of the district- and domestic heat pump depend on the assumption of a 50\% incidence of hydro-generated electricity in the system's mix.

Why is electrical heating then used? Because, under certain circumstances, "it is cheap": in this perspective, its adoption actually satisfies rule 20, in that the monetary cost for an electrical stove is much lower than that required by a solar thermal plant or by a waste-heat recovery system (including district heating).

\subsection{Gasoline and Diesel Engines Hot Gas Discharge}

Without exceptions, hot gas discharges from internal combustion engines are at an average temperature of 500-1100 K (spark-ignited) and 470-800 (self-ignited). The exhaust system operates as a passive cooler, and the gases are expelled from the vehicle at a substantially lower temperature. This violates rules 3, 9 and 21 (exhaust losses are a major source of irreversibility), and does not abide by the suggestion of rules 6 and 8 . The solution is of course implicit in rule 6: a portion of the discarded heat might be used to feed a bottoming electricity-generating cycle (possibly, an ORC) mounted downstream of the engine that feeds for instance the on-board auxiliaries or even contributes to a hybrid propulsion mode: at present, this solution is considered to be too expensive and -though the subject of extensive research activity- is not implemented in commercial vehicles.

\subsection{Gas Turbine Hot Gas Discharge}

The temperature of exhaust gases from standard regenerated gas turbine plants range from 800 to $1000 \mathrm{~K}$. Modern combined-cycle plants make use of the suggestion of rule 6, reaching higher exergy efficiency and substantially reducing the exergy destruction in the process. This practice is generally not applied to small gas turbine installations (micro-turbines generating less than $100 \mathrm{~kW}$ ) because of costing considerations.

\subsection{Desalination by Reverse Osmosis}

$\mathrm{RO}$ is becoming more and more popular, and it is claimed that both its specific energy and exergy use is inferior to that of other methods, e.g. MSF. Accepted values are 3-6 $\mathrm{kWh}$ electrical $/ \mathrm{m}^{3}$ for RO and $\left(10 \mathrm{kWh}_{\text {thermal }} / \mathrm{m}^{3}+1.8 \mathrm{kWh}\right.$ electrical $\left./ \mathrm{m}^{3}\right)$ for MSF $[1,5,18,19]$. Since $1 \mathrm{kWh}$ of electricity is accounted for 
as $1 / \eta_{\text {system }} \cong 2.4 \mathrm{kWh}$ thermal, and reasoning on the basis of the average values in the above ranges, the energy comparison gives a ratio $\mathrm{E}_{\mathrm{RO}} / \mathrm{E}_{\mathrm{MSF}} \cong 4.5 * 2.4 /(10+1.8 * 2.4)=0.75$. For a heat source (steam) at $400 \mathrm{~K}$ (approximately $130 \mathrm{C}$ ), the thermal exergy input amounts to about $0.28 \mathrm{kWh} / \mathrm{m}^{3}$, and the exergy ratio becomes $\mathrm{Ex}_{\mathrm{RO}} / \mathrm{Ex}_{\mathrm{MSF}} \cong 4.5 /(10 * 0.28+1.8)=0.98 .^{2}$

Leaving aside scale-up considerations, the Sama-Szargut rules suggest instead to use MSF, especially because (rule 6) the thermal input to the MSF process can be provided by steam extracted from a backpressure turbine. But rule 20 suggests caution, because the investment costs for MSF plants are far greater than for RO of equivalent size (and furthermore, small MSF plants have even higher capital cost per $\mathrm{m}^{3}$ of distillate). The issue is therefore "undecided" under the rules, and recourse to other methods, like Thermo-Economics, is required.

\subsection{Gas Turbine Blades Cooling by Compressor's Air}

Modern gas turbine plants have ever higher turbine inlet temperatures (TIT), and material limitations demand that some form of cooling is implemented for combustion liners and first- and second row stators and rotors. By far the most common solution is to extract a small amount (2-7\% of the total mass flow rate) of air from the last compressor stage and channel it through the liners and blades to perform convection -or film, or impact- cooling. But such a practice violates rule 18, because the cooling air has been compressed using mechanical exergy. It also violates rules 2 (it enforces mixing), 11 (the $\mathrm{c}_{\mathrm{pm}}$ of the two streams are widely different) and 14 (the cooling holes are chocked and introduce throttling). To a minor extent, it violates rule 1 as well, because the temperature difference between the cooling air and the gas stream is about 400-700 K. Two alternatives might be that of lowering the TIT, but this decreases -ceteris paribus- the power output and the efficiency of the plant, or/and to use ceramic blades, which pose structural limits and are also more costly.

\subsection{Separate Heating and Cooling Systems in the Residential and Commercial Sector}

Commercial, institutional and residential buildings are usually designed with two separate space conditioning systems: one for heating and one for cooling. No matter what systems are selected, rule 6 (cogeneration) is violated.

\subsection{Steam Throttling in Steam Powerplants and in Refrigerating Machines}

Most steam powerplants are endowed with primary steam throttling to facilitate operation at partial load. This violates rule 14. Back-pressure turbines are also customarily throttled, as are the steam extractions. Refrigeration plants throttle the vapour downstream of the condenser, also violating the same rule: in this case, the solution of installing an expander is avoided in smaller plants in essence because of cost reasons.

\footnotetext{
${ }^{2}$ Curiously, the exergy use in desalination processes is a highly debated issue, and values even substantially different from the above are found in the literature.
} 


\section{A New Costing Paradigm}

Why are the Sama-Szargut rules so often disregarded? Are they so detached from real-life engineering to be impractical? Thermodynamicists think they are not, and my contention is that the reason for which they are not implemented in practice is the factoring of a non-thermodynamic parameter (monetary cost) in every engineering design decision. In this section, I will argue that a paradigm shift, namely the introduction of a properly calculated primary exergy cost, can resolve the issue and lead to designs that abide by all of the rules in the list (with the exception of \#20 that needs rephrasing).

It is useful to start from a global system perspective and ask the following question: what is the driving potential that sustains the operation of a biological entity? The rather obvious answer is "exergy", because all living systems are known to absorb it from the surroundings and to destroy a large portion of this input to perform their biological tasks. Lotka [11,12] was the first to explicitly posit that living beings can operate inasmuch, and as long as, they can avail themselves of a sufficient flux of what he called "available energy”. Odum [16] applied Lotka's intuition to human societies, and proposed to measure immaterial "products” like Labour and Capital using a physical numeraire, a process-related space- and time integral of solar energy that he named emergy: this choice turned out to be unfortunate because it precludes the possibility of performing a rigorous comparison between different dissipative process chains. This author proposed [26] to combine Lotka's and Odum's ideas, and introduced the extended exergy (EE), defined as the amount of equivalent primary exergy needed to generate a product. EE is a quantity expressed in $\mathrm{J}$ (its flux in $\mathrm{W}$ and its specific counterpart ee in $\mathrm{J} /$ unit) that measures the primary resource consumption by means of a proper thermodynamic procedure, and succeeds in quantifying the so-called externalities (Labour, Capital and Environmental remediation cost) in a systematic and reproducible way. A system analysis based on EE results in an accounting method called Extended Exergy Accounting (EEA), and its details are described for example in [20,26-28]. What is of interest for the purpose of the present discussion is that the EE of a product includes (in a space- and time integral sense):

a) the total exergy influx during operation;

b) the primary equivalent exergy that is required to produce, maintain and decommission the equipment;

c) the primary equivalent exergy required to sustain the labour force;

d) the primary equivalent exergy required to generate the necessary monetary capital;

e) the primary equivalent exergy needed for the environmental remediation actions.

EEA has been successfully applied to analyze individual components, processes, societal sectors and entire complex systems: here, after a brief recapitulation of the EEA principles, I will try to demonstrate that it provides an stronger incentive to designers to abide by the Sama-Szargut rules.

\footnotetext{
${ }^{3}$ Not “energy", because an energy balance cannot properly describe the dissipative dynamics of living beings; not entropy, because without an energy "level” and "intensity” to be associated with, an entropy analysis is only qualitative [4].
} 


\subsection{The Basic Postulates}

The EEA method is based on two fundamental postulates.

$1^{\text {st }}$ postulate: In any Society, the global influx of exergy resources $E_{i n}$ is primarily "used" to sustain the workers who generate Labour. In exergy terms:

$$
\dot{E}_{L}=\alpha \dot{E}_{\text {in }}
$$

$\underline{2}^{\text {nd }}$ postulate: The exergy flux needed to generate the monetary circulation M2 within a Society is proportional to the Labour exergy. In exergy terms:

$$
\dot{E}_{K}=\beta \dot{E}_{L}
$$

Where both $\alpha$ and $\beta$ are numerical factors that depend on the type of societal organization, the historical period, the technological level and the geographic location of the Society: they are, in other terms, time- and space dependent model parameters (for a pre-monetary society, $\alpha$ is high and $\beta=0$; for a modern strongly tertiarized society, $\alpha$ is rather low and $\beta$ is high). Their value is not assigned by the theory, and must be calculated from econometric data.

\subsection{How to Compute the Equivalent Exergy Values}

The equivalent primary exergy resource that goes into one work-hour is opbtained by dividing the net total exergy flux that goes into Labour by the cumulative number of work-hours generated in a given period of time:

$$
e e_{L}=\frac{\alpha \dot{E}_{\text {in,net }}}{N_{w h}}
$$

\section{[J/workhour]}

Similarly, to compute the equivalent primary exergy resource that goes into one monetary unit, we need to divide the total exergy flux that goes into Capital by the cumulative monetary circulation maintained for that period of time:

$$
e e_{K}=\frac{\alpha \beta \dot{E}_{\text {in,net }}}{M_{2}}
$$

Notice that:

a) both $\alpha$ and $\beta$ can be accurately computed from econometric data: their calculation is clearly iterative, because it is necessary to calculate all the exergy fluxes that go into the generation of a work-hour and of 1 monetary unit;

b) double accounting is excluded, because $\dot{E}_{\text {in,net }}$ is „used“ solely to generate Labour;

c) monetary circulation is a "by-product" of Labour. This allows to treat pre-monetary societies (by setting $\beta=0$ in eq. 2). 
For the so-called „environmental externality“, the EEA method adopts a „remediation approach“: the equivalent primary exergy resource that goes into the elimination of the effects of some effluent „X“ into the environment is equal to the EE of the (real or virtual) process needed to eliminate the „pollution“ by manipulating $\mathrm{X}$ so that its thermal, chemical, mechanical... exergy is approximately equal to 0 at the discharge site.

The EE-cost of a product $\mathrm{P}$ is calculated using the same cost balance equations of the Thermo-

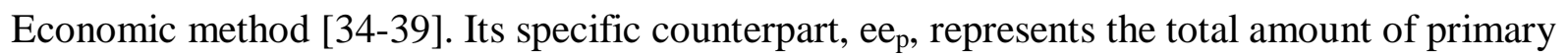
equivalent exergy needed to generate one unit $(\mathrm{J})$ of product exergy.

\subsection{EEA and the Sama-Szargut Rules}

Let us reexamine the first four cases cases of violation of the Sama-Szargut rules presented in section 3.1-3.7 from an EEA perspective. The calculations presented here below are based on several „lumped“ assumptions on the process under examination and therefore they are obviously not very accurate: but the degree of approximation is good enough to draw some preliminary conclusions.

\subsubsection{Electric Heaters}

The procedure that leads to the calculation of the exergy efficiency of an electric heater is quite simple [8]: the chain of "production" of the final exergy flux (the product) is shown in figure 2: the efficiency of the powerplant is multiplied by that of the distribution net and by that of the final user. It is useful to reason in terms of "cost" instead of efficiency, the "exergy cost" being the amount of used exergy (the fuel) divided by the exergy dispatched to the final user (the product):

$$
c_{P 3}=\frac{F 1}{P 3}=\frac{F 1}{P 1} \frac{P 1}{P 2} \frac{P 2}{P 3}=1.85 * 1.07 * 14.28=28.3 e_{F 1}
$$

Using for $\mathrm{e}_{\mathrm{F} 1}$ (oil) the value 1.1 [31] we find that each Joule of delivered product has a cost of over 30J of primary exergy. Monetary and environmental costs are not included.

In an EEA perspective, the system's boundary is enlarged to encompass all of the upstream processes that lead to the production of the oil (this is the procedure introduced by Szargut [29] and known under the name of “cumulative exergy content”). In addition, the externalities are explicitly included: figure 3 reports a simplified flow diagram. The cost calculation now is based on the exergy of the oil in the well, $e_{\text {crude, }}$ and becomes more involved because at each step we have to account for the labour-, capital- and environmental remediation equivalent exergies "invested" in the process. For the sake of the present discussion, let us assume the following ee-costs ${ }^{4}$ :

$$
c_{P b}=\frac{e e_{P b}}{e_{c r u d e}}=2.24 ; \quad c_{P c}=\frac{e e_{P c}}{e e_{P b}}=1.93 ; \quad c_{P d}=\frac{e e_{P d}}{e e_{P c}}=1.07 ; \quad c_{P 3}=\frac{e e_{P 3}}{e e_{P d}}=14.28
$$

\footnotetext{
${ }^{4}$ The data upon which these estimates are based have been extracted from [7,15,19] for the oil extraction/refining chain; from [28] for the transportation costs and from [6] for the solar hydbrid panel.
} 
Where these values include for each step the exergy destruction, the equivalent labour- and capital exergy and the primary equivalent environmental exergy cost, and are provided here without justification: they may be not accurate, but their order of magnitude is sufficient for the present scope.

$$
e e_{P 3}=e_{\text {crude }} C_{P b} c_{P c} c_{P d} c_{P 3}=2.24 * 1.93 * 1.07 * 14.28=66 e_{\text {crude }}
$$

The value of $\mathrm{ee}_{\mathrm{p} 3} / \mathrm{C}_{\mathrm{P} 3}$ is equal to $(66 * 51000) /(28.3 * 1.1 * 45000)=2.4$ and indicates that the neglection of externalities underestimates the real cost of the product „,heating“ by $140 \%$.

To repeat the calculation for the other heating systems, we would need a detailed database of labour, operating and capital costs for each subunit, which is not available at the moment. As an illustrative example, if a solar hybrid panel coupled with floor panels is used as the heating unit, its efficiency being approximately $12 \%$ [6], the cost factors become ${ }^{5}$ :

$$
c_{P x}==\frac{e e_{P e l}}{e_{\text {sun }}}=12.5 ; \quad c_{P 3}=\frac{e e_{P 3}}{e e_{P y}}=8.33
$$

and the costs of the products are:

$$
\begin{gathered}
c_{P 3}=c_{P x} e_{\text {sun }}=12.5 * 8.33 * e_{\text {sun }}=104 e_{\text {sun }} \\
c_{P e l}=c_{P x}=10 e_{\text {sun }}
\end{gathered}
$$

Intuitively, from the point of view of the biosphere, 66J of crude oil exergy have "stored" much more that $104 \mathrm{~J}$ of solar irradiation exergy: but the exact calculation is neither easy nor devoid of subjective choices, and therefore an accurate assessment of the reduction of the primary exergy cost for the same heating load is not possible here. What is clear though is that if rules 1, 9, 17 and 21 are abided by, a more rational resource use is attained.

\subsubsection{Gasoline and Diesel Engines Hot Gas Discharge}

By similar reasoning, assuming that the monetary cost of an vehicular ORC device amounts to about $800 €$ and using the $e_{\mathrm{L}}=153,95 \mathrm{MJ} /$ workhour and $\mathrm{ee}_{\mathrm{K}}=33.15 \mathrm{MJ} / €$ (values are for Turkey 2006, as calculated in [29]), for a 100kW engine (purchase cost about 2000€) we obtain at full load operation (figure 4):

Extra power provided by the ORC system, $\mathrm{P}_{\mathrm{ORC}}=0.25 \mathrm{P}=25 \mathrm{~kW}$

Equivalent primary exergy of the engine without ORC, $\mathrm{EE}_{\mathrm{ENG}}=\mathrm{ee}_{\mathrm{K}} * 2000=2.1 \mathrm{~kW}$

Extra equivalent primary exergy of the ORC addition, $\Delta \mathrm{EE}_{\mathrm{ORC}}=\mathrm{ee}_{\mathrm{K}} * 800=0.9 \mathrm{~kW}$

So that, for the same fuel flow rate, and neglecting the improvement due to the reduction of the specific $\mathrm{g}_{\mathrm{co} 2} / \mathrm{kWh}$ emissions, the primary equivalent exergy cost of the $\mathrm{kWh}$ becomes;

${ }^{5}$ In the additional -arbitrary- assumption of $\mathrm{C}_{\mathrm{PVH}, \mathrm{el}}=\mathrm{C}_{\mathrm{PVH}}$,heat 


$$
c_{P+P_{\text {ORC }}}=\frac{e e_{P b} * \mathrm{~m}_{\mathrm{f}}+\mathrm{EE}_{\mathrm{Eng}}+\mathrm{EE}_{\mathrm{ORC}}}{\mathrm{P}+\mathrm{P}_{\mathrm{ORC}}}=\left(\frac{e e_{P b} * \mathrm{~m}_{\mathrm{f}}+\mathrm{EE}_{\mathrm{Eng}}}{\mathrm{P}}+\frac{\mathrm{EE}_{\mathrm{ORC}}}{\mathrm{P}}\right) \frac{\mathrm{P}}{\mathrm{P}+\mathrm{P}_{\mathrm{ORC}}}
$$

whereas

$$
c_{P}=\frac{e e_{P b} * \mathrm{~m}_{\mathrm{f}}+\mathrm{EE}_{\mathrm{Eng}}}{\mathrm{P}}
$$

Equations 10) \& 11) show that the installation of a vehicular ORC leads to an advantage in terms of primary exergy consumption if $c_{P+P_{O R C}}<c_{P}$, i.e. if $\mathrm{EE}_{\mathrm{ORC}}<\mathrm{P}_{\mathrm{ORC}} c_{P}$. In the above example, we obtain:

$$
c_{P}=8.3 ; \quad c_{P+P_{\text {ORC }}}=6.77
$$

And the advantage (predicted by rules 3, 6 and 9) is apparent. Incidentally, the EEA method offers additional insight, in that it provides an upper limit to the installation cost of the ORC unit beyond which is inclusion is no longer profitable in terms of exergy savings.

\subsubsection{Gas Turbine Hot Gas Discharge}

The advantage of recovering a portion of the exhaust exergy from a gas turbine by inserting a bottoming steam plant can be deduced by a similar reasoning as that discussed in the previous section.

\subsubsection{Desalination by Reverse Osmosis}

In an EEA perspective, the cost of fuel delivered to the MSF plant is 2.24e $\mathrm{e}_{\text {crude }}$ (see section 4.3.1), while the cost of electricity is $4.63 \mathrm{e}_{\text {crude. }}$. Since the investment costs are comparable -about 1000$1300 € /\left(\mathrm{m}^{3} /\right.$ day) for both type of plants $[1,5,18,41]$-, the comparison can be based only on the energyand environmental remediation costs ${ }^{6}$. Following the procedure outlined in the previous sections, and considering the ee $\mathrm{env}_{\mathrm{e}}$ costs:

- $\quad$ ee-cost of environmental remediation $\mathrm{RO}$, ee $\mathrm{env}_{\mathrm{RO}}=0.13$

- $\quad$ ee.cost of environmental remediation MSF, ee env,NSF $=0.175$

$\left(1 \mathrm{~m}^{3}\right.$ of distillate has an exergy $\left.\mathrm{e}_{\text {dist }}=4000 \mathrm{~kJ} / \mathrm{m}^{3}\right)$, the final costs are:

$\mathrm{ee}_{\mathrm{RO}}=18.97$

ee $\mathrm{MSF}$, non-cogen $=32.67$

$\mathrm{ee}_{\mathrm{MSF}, \mathrm{cogen}}=23.47$

And indicate that, while non-cogenerated MSF is extremely exergivorous, cogenerated MSF and $\mathrm{RO}$ are comparable in terms of resource costs $\left(\mathrm{ee}_{\mathrm{RO}} / \mathrm{ee}_{\mathrm{MSF}, \mathrm{cogen}}=0.81\right)$. The Sama-Szargut rules, as discussed in section 3.4, discourage the use of non-cogenerated MSF and are neutral with regard to the choice between cogenerated MSF and RO.

Consider that a PV-powered RO facility or a solar-thermal MSF plant would be the solutions suggested by the rules. There are though no available data to provide an EEA analysis here.

\footnotetext{
${ }^{6}$ Calculated here on the basis of the CO2 emission trading costs 2013 [42].
} 


\section{Conclusions}

Engineering design is guided by the axiom of generating the specified output with the minimal expenditure. The EEA paradigm calculates this "expenditure” in terms of primary equivalent exergy resources, and thus privileges solutions that minimize the exergy footprint of the product. Since EEA is based on a systematic use of exergy budgets, its correct application automatically enforces the SamaSzargut rules, provided they are consistently interpreted in a purely exergetic sense. Therefore, it is proposed here that rule 20 be rephrased as Accept an exergy destruction only if it is indispensable for the reduction of the total EE cost. Exergy destructions not having any justification in terms of primary resource savings should be treated as the result of an engineer's error.

\section{Conflicts of Interest}

The author declares no conflict of interest.

\section{References and Notes}

1. F. Banat, 2007: Economic and technical assessment of desalination technologies, Proc. Seminar on Energy Systems Analysis, Geneve, 6-8 june

2. J. Beyer,1972: Zur Aufteilung der Primärenergiekosten in Koppelprozessen auf Grundlage der Strukturanalyse, Energieanw., v.21, n.6, 179-183, June

3. L. Borel, D. Favrat, 2010: Thermodynamics and energetics for engineers, London : CRC Press

4. F. Bosnjakovic, ed., 1961: Fachheft Exergie, Die praktische Bedeutung der Exergie, BWK, v.13, n.11, 481-528

5. J. Diaz-Caneja, M. Fariñas, A. Jimenez, 2005: Spanish cost data illustrate RO’s competitiveness, Int. Des. \& water reuse quarterly, v.15, n.1, 10-17

6. E. Cheremnykh, M. Cianfrini, E. Sciubba, C. Toro, 2013: An integrated exergy approach for the optimal matching of internal and external heating plants in building conditioning systems, Energy and Buildings v.62, 638-647

7. EIA - U.S. Energy Information Administration, 2013: Petroleum Marketing Monthly, data for September 2013, http://www.eia.gov/petroleum/marketing/monthly/

8. D. Favrat, 2007: The exergy approach in a legal framework, Proc. Seminar on Energy Systems Analysis, Geneve, 6-8 june

9. T.J. Kotas, 1985: The exergy method of thermal plant analysis, Butterworths, Academic Press, London

10. I.L. Lietes, D.A. Sama, N. Lior, 2003: The Theory and Practice of Energy Saving in the Chemical Industry: Some Methods for Reducing Thermodynamic Irreversibility in Chemical Technology Processes, Energy, v. 28, 55-97

11. A.J. Lotka, 1922: Contribution to the energetics of evolution, Proc. Nat. Acad. Sci., v.8, 147-151

12. A.J. Lotka, 1922: Natural selection as a physical principle, Proc. Nat. Acad. Sci., v.8, 151-154

13. E. Mohseni-Languri, H. Taherian, R. Masoodi, J.R. Reisel, 2009: An Energy and Exergy study of a Solar Thermal Air Collector, Thermal Science, v.13, n.1, 205-216 
14. L.T. Ngaw, D.A. Sama, 1998: Design of Crude Oil Distillation Heat Exchanger Networks Using Second Law Insights, Proc. ECOS'98, Nancy, France, Inst. Nat. Polyt. de Lorraine, July, 141-156

15. M. Nuhu, A.S. Olawale, N. Salahudeen, A.Z. Yusuf, Y. Mustapha, 2012: Exergy and Energy Analysis of Fluid Catalytic Cracking Unit in Kaduna Refining and Petrochemical Company, Int.

J. Chem. Eng. and Applications, v.3, n.6, 441-445

16. H.T. Odum, E.C. Odum, 1981: Energy Basis for Man and Nature, McGraw-Hill NY

17. K. Quteishat, 2009: Energy for Desalination, Proc. Stockholm Water Week, Aug.18, Stockholm, Sweden

18. M.R. Qtaishat, F. Banat, 2013: Desalination by solar powered membrane distillation systems, Desalination, n.308, 186-197

19. R. Rivero, C. Rendon, L. Monroy, 1999: The Exergy of Crude Oil Mixtures and Petroleum Fractions: Calculation and Application, Int.J. Applied Thermodynamics, v.2, n.3, 115-123

20. M. Rocco, E. Colombo, E. Sciubba, 2014: Advances in exergy analysis: a novel assessment of the Extended Exergy Accounting method, Applied Energy v.113, 1405-1420

21. D.A. Sama, 1980: Looking at the True Value of Steam, Oil and Gas J., v. 78, n. 15, 103-119

22. D.A. Sama, 1983: Cost Savings Through Lost-Work Analysis at Heat Exchangers. Energy Progress, Vol. 3, No. 4, pp. 212-219, December.

23. D.A. Sama, 1992: A Common-Sense 2nd Law Approach to Heat Exchanger Network Design, Proceedings of ECOS '92, Zaragoza, Spain, pp. 329-338, ASME, June.

24. D.A.Sama, 1995: The Use of the Second Law of Thermodynamics in Process Design, ASME J. En. Res. Techn., v.117, 179-185, September.

25. D.A. Sama, S. Qian, R.A. Gaggioli, 1989: A Common-sense Second Law Approach for Improving Process Efficiencies, Proc. TAIES'89, Beijing, China, Int.l Acad. Pub./Pergamon Press, June, 520-531

26. E. Sciubba, 2001: Beyond thermoeconomics? The concept of extended exergy accounting and its application to the analysis and design of thermal systems, Int. J. Exergy, v.1, 68-84.

27. C. Seckin, E. Sciubba, A. Bayulken, 2012: An application of the Extended Exergy Accounting method to the Turkish Society, year 2006, Energy v.40, 151-163

28. C. Seckin, E. Sciubba, A. Bayulken, 2013: Extended Exergy Analysis of Turkish Transportation Sector, J. Cleaner Production, v.47, 422-436.

29. J. Szargut, D.R. Morris, F.R. Steward, 1988: Exergy Analysis of Thermal, Chemical, and Metallurgical Processes, Hemispere Publ., New York/Springer-Verlag, Berlin

30. J. Szargut, D.A. Sama, 1995: Practical Rules of the Reduction of Energy Losses Caused by the Thermodynamic Imperfections of Thermal Processes, Proc. of The II Int. Thermal Energy Congress, Agadir, Morocco, June, v. 2, 782-785

31. J. Szargut, T. Styrylska, 1964: Angenäherte Bestimmung der Exergie von Brennstoffen, BWK, v.16, n.12, 589-596

32. G. Tsatsaronis, 1984: Combination of exergetic and economic analysis in energy conversion processes, Proc. European Congress on Energy Economics \& Management in industry, Algarve, Portugal, April 2-5, v.1, 151-157

33. G. Tsatsaronis, M. Winhold, 1985: Exergoeconomic Analysis and Evaluation of Energy Conversion Plants. Part I- A New General Methodology, Energy, v.10, n.1, 69-80 
34. G. Tsatsaronis, F. Cziesla, Z. Gao, 2003: Avoidable Thermodynamic Inefficiencies and Costs in Energy Conversion Systems, Part 1: Methodology, Proc. ECOS 2003, Techn. U. of Denmark, Copenhagen, July v. 2, 809-814

35. A. Valero, M.A. Lozano, M. Muñoz, 1986: A general theory of exergy savings - I. On the exergetic cost, Proc. ASME Computer-Aided Engineering of Energy Systems, v. 3 - Second law analysis and modelling, Ed. R.A. Gaggioli, 1-8

36. A. Valero, M. Muñoz, M.A. Lozano, 1986: A general theory of exergy saving. II. On the thermoeconomic cost, Proc. ASME-AES, Computer-Aided Engineering and Energy Systems. Vol. 3: Second Law Analysis and Modelling. Ed. R.A. Gaggioli, 9-16

37. A. Valero, M. Muñoz, M.A. Lozano, 1986: A general theory of exergy saving. III. Energy saving and thermoeconomics, Proc. ASME-AES, Computer-Aided Engineering and Energy Systems. Vol. 3: Second Law Analysis and Modelling. Ed. R.A. Gaggioli, 17-21

38. http://vtsindustrial.com/boiler_estimate.html, accessed 8 December, 2013

39. http://www.co2prices.eu/, accessed 8 December, 2013

\section{Appendix}

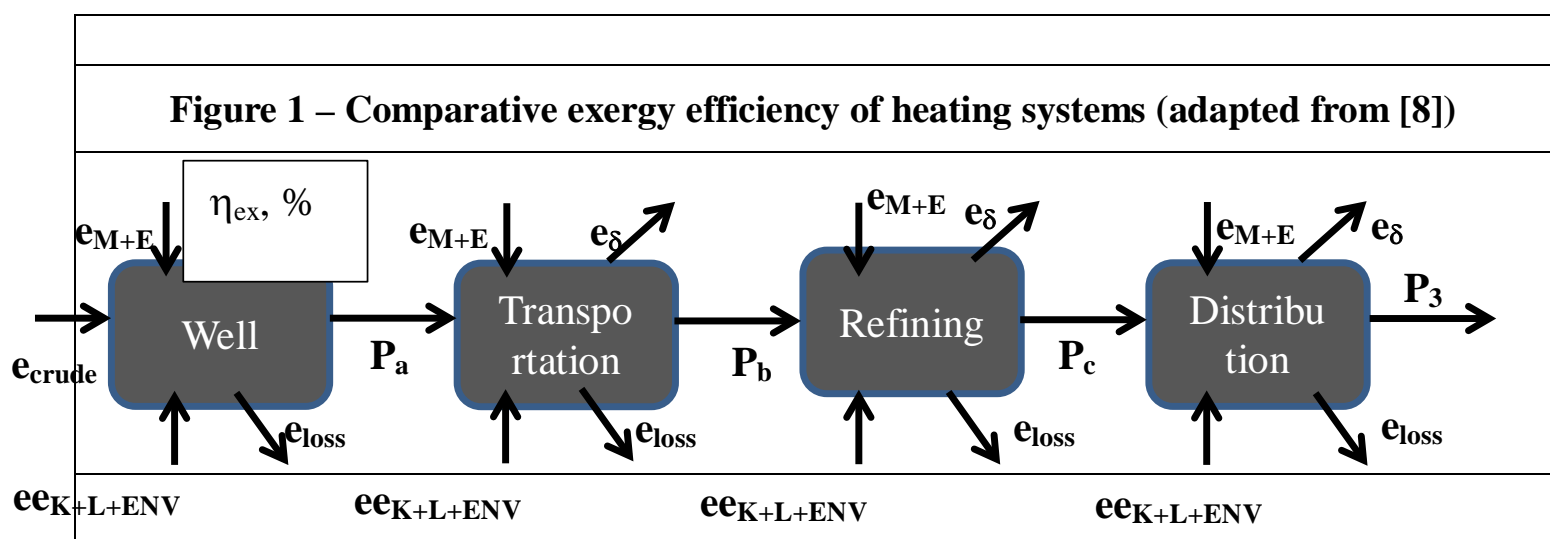

Figure 2 - The chain of the generation of electricity from the oil source

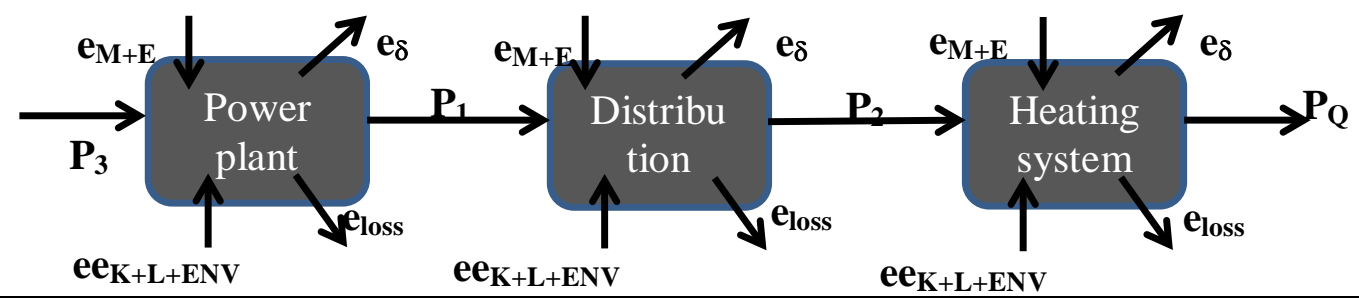

Figure 3 - Principle scheme for the calculation of the EEA cost of a heating system

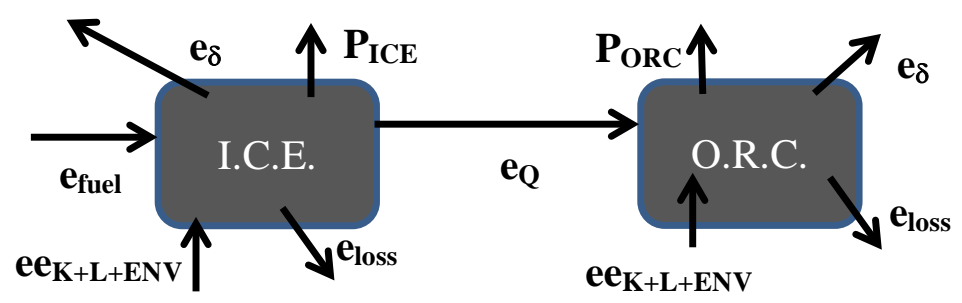

Figure 4 - Scheme of an ORC-based on-board heat recovery system 
(C) 2014 by the authors; licensee MDPI, Basel, Switzerland. This article is an open access article distributed under the terms and conditions of the Creative Commons Attribution license (http://creativecommons.org/licenses/by/3.0/). 